University of Nebraska - Lincoln

DigitalCommons@University of Nebraska - Lincoln

Publications from USDA-ARS / UNL Faculty

U.S. Department of Agriculture: Agricultural

Research Service, Lincoln, Nebraska

2013

\title{
A new genetic linkage map of barley (Hordeum vulgare L.) facilitates genetic dissection of height and spike length and angle
}

\author{
Emir Islamovic \\ USDA-ARS, Emir.Islamovic@ars.usda.gov \\ Donald E. Obert \\ Limagrain Cereal Seeds \\ Rebekah E. Oliver \\ North Dakota State University \\ Juliet M. Marshall \\ University of Idaho \\ Kelci J. Miclaus \\ SAS Institute Inc., JMP Genomics Development \\ See next page for additional authors
}

Follow this and additional works at: https://digitalcommons.unl.edu/usdaarsfacpub

Islamovic, Emir; Obert, Donald E.; Oliver, Rebekah E.; Marshall, Juliet M.; Miclaus, Kelci J.; Hang, An; Chao, Shiaoman; Lazo, Gerard R.; Harrison, Stephen A.; Ibrahim, Amir; Jellen, Eric N.; Maughan, Peter J.; Brown, Ryan H.; and Jackson, Eric W., "A new genetic linkage map of barley (Hordeum vulgare L.) facilitates genetic dissection of height and spike length and angle" (2013). Publications from USDA-ARS / UNL Faculty. 1419.

https://digitalcommons.unl.edu/usdaarsfacpub/1419

This Article is brought to you for free and open access by the U.S. Department of Agriculture: Agricultural Research Service, Lincoln, Nebraska at DigitalCommons@University of Nebraska - Lincoln. It has been accepted for inclusion in Publications from USDA-ARS / UNL Faculty by an authorized administrator of DigitalCommons@University of Nebraska - Lincoln. 


\section{Authors}

Emir Islamovic, Donald E. Obert, Rebekah E. Oliver, Juliet M. Marshall, Kelci J. Miclaus, An Hang,

Shiaoman Chao, Gerard R. Lazo, Stephen A. Harrison, Amir Ibrahim, Eric N. Jellen, Peter J. Maughan, Ryan H. Brown, and Eric W. Jackson 


\title{
A new genetic linkage map of barley (Hordeum vulgare L.) facilitates genetic dissection of height and spike length and angle
}

\author{
Emir Islamovic ${ }^{\mathrm{a}}$, Donald E. Obert ${ }^{\mathrm{c}}$, Rebekah E. Oliver ${ }^{\mathrm{k}}$, Juliet M. Marshall ${ }^{\mathrm{j}}$, \\ Kelci J. Miclaus ${ }^{\mathrm{d}}$, An Hang ${ }^{\mathrm{a}, 1}$, Shiaoman Chao ${ }^{\mathrm{f}}$, Gerard R. Lazo ${ }^{\mathrm{g}}$, Stephen A. Harrison ${ }^{\mathrm{h}}$, \\ Amir Ibrahim $^{\mathrm{i}}$, Eric N. Jellen ${ }^{\mathrm{e}}$, Peter J. Maughan ${ }^{\mathrm{e}}$, Ryan H. Brown ${ }^{\mathrm{b}}$, Eric W. Jackson ${ }^{\mathrm{b}, *}$ \\ a USDA-ARS, 1691 S. 2700 W., Aberdeen, ID 83210, United States \\ b General Mills, Inc., 150 Research Campus Dr., Kannapolis, NC 28081, United States \\ c Limagrain Cereal Seeds, 9020 Grant Road, Battle Ground, IN 47905, United States \\ d SAS Institute Inc., JMP Genomics Development, 100 SAS Campus Dr., Cary, NC 27513, United States \\ e Brigham Young University, Department of Plant and Wildlife Sciences, Provo, UT 84602, United States \\ ${ }^{f}$ USDA-ARS, 1605 Albrecht Blvd., Fargo, ND 58105, United States \\ ${ }^{g}$ USDA-ARS, 800 Buchanan St., Albany, CA 94710, United States \\ ${ }^{\mathrm{h}}$ Louisiana State University, School of Plant, Environmental and Soil Sciences, 221 M.B. Sturgis, Baton Rouge, LA 70803, United States \\ i Department of Soil and Life Sciences, Texas AEM University, 430C Heep Center, College Station, TX 77843, United States \\ j University of Idaho, Department of Plant, Soil, and Entomological Sciences, 1776 Science Center Dr. Suite 205, Idaho Falls, ID 83660-9637, United States \\ ${ }^{\mathrm{k}}$ Department of Plant Sciences, North Dakota State University, 166 Loftsgard Hall, Fargo, ND 58108-6050, United States
}

\section{A R T I C L E I N F O}

\section{Article history:}

Received 26 March 2013

Received in revised form 31 May 2013

Accepted 1 June 2013

\section{Keywords:}

Molecular markers

Genetic linkage map

QTL mapping

Barley

Height

Spike

\begin{abstract}
A B S T R A C T
Plant height and spike length and angle are important agronomic traits in the production of barley (Hordeum vulgare L.) due to strong correlations with lodging and disease. The objective of this study was to use QTL analysis to identify genetic regions associated with each trait in a recombinant inbred line (RIL) mapping population derived from a cross of Falcon by Azhul. Falcon is a spring six-row hulless feed barley with long spikes displaying obtuse angles, while Azhul is a spring dwarf, six-row hulless food barley with short spikes displaying acute angles. The population was genotyped using SNP, DArT and SSR markers and quantitative trait loci (QTL) were detected on chromosomes $2 \mathrm{H}(102.8 \mathrm{cM}$, spike length), $3 \mathrm{H}(89.2 \mathrm{cM}$, plant height and 38.2, spike angle and length), $4 \mathrm{H}(19.0 \mathrm{cM}$, spike length), and $5 \mathrm{H}$ (106.7 cM, spike angle). In conclusion, we developed a barley genetic map, which incorporated SNP, DArT and SSR markers, for detection of height and spike length and angle QTL. Three spike angle, one spike length and one plant height QTL were novel and by using comparative genomics we identified possible candidate genes involved in gibberellic acid signaling and auxin- and ethylene-responsive pathways. This knowledge can be used to generate suitable markers for barley breeding improvement.
\end{abstract}

Published by Elsevier B.V.

\section{Introduction}

Barley (Hordeum vulgare L.) is the fourth most abundant cereal in world. The crop is adapted to various environments and is used as feed for livestock, malted beverages and food products. US barley production is currently around 320 million bushels per year with an estimated value of $\$ 760$ million (National Barley Grower Association).

A key trait in developing new barley varieties with improved agronomics, including yield, is plant height. Plant height directly

\footnotetext{
* Corresponding author. Tel.: +1 7042502614 .

E-mail addresses: Eric.Jackson@genmills.com, Emir.Islamovic@ars.usda.gov (E.W. Jackson).

1 Retired.
}

relates to lodging thus reducing this trait would allowed agricultural practices focused on increased yield, such as dense planting and increased use of fertilizer. Genetic studies have been done to identify key alleles involve in this important trait. Chutimanitsakun et al. (2011) and Dahleen et al. (2012) identified QTL affecting plant height on chromosome $1 \mathrm{H}$ at $131 \mathrm{cM}, 2 \mathrm{H}$ at 65,81 and $156 \mathrm{cM}$, $3 \mathrm{H}$ at 51 and $120 \mathrm{cM}, 4 \mathrm{H}$ at $188 \mathrm{cM}$ and $6 \mathrm{H}$ at $100 \mathrm{cM}$. Extensive research in model species, including barley, has discovered that most of the genes involved in height were also involved in the gibberellic acid (GA) biosynthetic and signal transduction pathways (Sakamoto et al., 2004; Peng et al., 1999; Helliwell et al., 2001; Gottwald et al., 2004; Spielmeyer et al., 2004). The sdw1/denso (semidwarf) gene encodes for GA-20 oxidase and it is one of the most studied genes in barley (Franckowiak and Pecio, 1992; Barua et al., 1993; Sasaki et al., 2002; Spielmeyer et al., 2002). It has been mapped to chromosome 3H (Barua et al., 1993; Laurie et al., 1993) 
and in a recent study it has been sequenced and applied as a diagnostic marker for selection of semidwarf gene in barley (Jia et al., 2009).

Spike length is an additional component affecting yield. Chutimanitsakun et al. (2011) study identified a major QTL on barley chromosome $2 \mathrm{H}$ at $156 \mathrm{cM}$ influencing spike length, grain number, plant height and grain yield. In the same study, on $1 \mathrm{H}$ at $157 \mathrm{cM}, 3 \mathrm{H}$ at $20 \mathrm{cM}, 5 \mathrm{H}$ at $138 \mathrm{cM}$ and $6 \mathrm{H}$ at $95 \mathrm{cM}$ affected only spike length. Work by Xue et al. (2010) identified QTL in the same region on chromosome $2 \mathrm{H}$ and $4 \mathrm{H}$ affecting both spike length and yield. Overall, this provides strong evidence of an underlying genetic mechanism on chromosome $2 \mathrm{H}$ and $4 \mathrm{H}$, however, suitable genetic markers for breeding application and underlying mechanisms of this trait were not provided.

Studies have suggested that spike angle can reduce fusarium head blight (FHB), which is a major disease significantly impacting barley production. For example, a FHB outbreak in 1993 caused yield losses of 70 million tons in the USA (McMullen et al., 1997). FHB also leads to contamination of barley with toxins (deoxynivalenol or DON), which can be a significant problem for barley producers and millers. A study showed that spike angle QTL partially overlapped with QTL for low fusarium head blight (FHB) severity and deoxynivalenol (DON) (Ma et al., 2000) while another study suggested that architecture of spike is associated with FHB resistance (Yoshida et al., 2005). Since spike length and angle require careful measurements at maturity, and are linked to important traits such as FHB and yield, markers tightly linked to these regions would be beneficial in order to sequence genes participating in these traits.

Over the last ten years, barley breeders have benefited from the availability of various genetic markers, including RFLP, AFLP, microsatellite, DArT, SNP, and STS (Kleinhofs et al., 1993; Rostoks et al., 2005; Wenzl et al., 2006; Hearnden et al., 2007; Marcel et al., 2007; Stein et al., 2007; Varshney et al., 2007; Potokina et al., 2008; Sato et al., 2009; Szücs et al., 2009). These markers facilitated numerous mapping studies which led to marker assisted breeding applications. Recently, barley marker resources were greatly expanded due to the development of Illumina GoldenGate SNP assays by the Barley Coordinated Agricultural Project. This alone provided a resource to interrogate several thousand alleles in tandem and led to the construction of a high density consensus map defined by 2943 SNP loci (Close et al., 2009). The same study showed a orthologous relationship between barley and rice chromosomes, which can lead to gene discovery for various traits linked to specific QTL regions, such as beta glucan content in barley grain (Islamovic et al., 2013).

The scope of this study was to use barley mapping population for detection of height and spike length and angle QTL based on SNP loci, use comparative genomic studies to identify candidate genes responsible for these traits, and present suitable markers for barley breeding improvement.

\section{Materials and methods}

\subsection{Plant material}

The Falcon/Azhul mapping population developed by Islamovic et al. (2013) to explore the genetics of beta glucan and amylose grain content was used in this study. Falcon (Helm et al., 1996) is a six-row hulless feed barley (Reg. No. CV-253, PI591612) released by the Field Crop Development Centre of Alberta Agriculture, Food and Rural Development, Lacombe, AB, Canada, and is well adapted to Idaho, with long spikes displaying obtuse angles. Azhul is a dwarf, six-row hulless food barley derived from mutation breeding and release by USDA ARS and the Arizona Agricultural Experiment Station (Dr. R. Thomas Ramage) with short spikes displaying acute angles. The population was developed via single seed descent in the greenhouse to the $F_{6}$ generation. Spikes of individual plants were not isolated until the $\mathrm{F}_{5}-\mathrm{F}_{7}$ stages, so outcrossing between sibs could have possibly occurred up to the $\mathrm{F}_{4}$ generation. $\mathrm{F}_{8}$ seed harvested from individual $\mathrm{F}_{7}$ plants was bulk increased to produce $F_{7: 9}$ seed for each FA RIL.

'Baronesse' and 'CDC Alamo' were used as controls in field experiments. Baronesse is a two-row hulled barley under U.S. Plant Variety Protection (PVP9300211) by Peterson Seed Company, Inc., with intermediate spike lengths displaying obtuse angels. CDC Alamo is a two-row hulless feed barley developed by the University of Saskatchewan, with long spikes displaying right angles.

\subsection{Field experiments}

Parents, RILs, and checks were planted in Baton Rouge, LA; College Station, TX; and Leeston, Irwell, New Zealand in the fall of 2008 and in Aberdeen and Tetonia, ID in the spring of 2009. A completely randomized block design was used at each location, with parental and check lines represented by four plots randomized within each block, and RILs represented by a single plot. Plots consisted of a single 1.2 meter row with $0.4 \mathrm{~m}$ spacing between rows. A wheat border consisting of four rows was planted around the entire experiment to minimize the edge effect.

Prior to ripening, four plants evenly spaced within each row were measured $(\mathrm{cm})$ for plant height using a standard meter stick $(5 \mathrm{~m})$. Measurements were taken from the crown of each plant to the tip of each spike, awns not included. At maturity, spike angles from three spikes were visually assessed by estimating the degree of deviation on a $0-10$ scale with $0=0^{\circ}$ and $10=180^{\circ}$ from the main tiller. Once the angles were collected, spikes were harvested and images of each spike were captured with a standard ruler $(\mathrm{cm})$ at a fixed distance of $27.9 \mathrm{~cm}$ using a Cannon Rebel digital camera (3072 $\times 2304$ pixels). Spike lengths excluding awns were measured in $\mathrm{cm}$ from each of the images using the ruler as a reference point. All measurements were recorded into a continuous data set so that plant height and spike length and angle were captured from the replicates at each location for ANOVA and marker/trait association.

\subsection{Genotyping}

Primary and secondary leaves were harvested from each parent and $F_{7}$ RIL plant used to derive the FA population. Harvested leaves from each line were placed into a $2.0-\mathrm{ml}$ microcentrifuge tube, and ground into a fine powder using a sterilized test tube pestle and liquid nitrogen. DNA was extracted using a CTAB protocol as previously described in Islamovic et al. (2013).

Barley microsatellites, diversity arrays technology (DArT), and single nucleotide polymorphism (SNP) markers were used to genotype each FA parent and RIL. Barley microsatellites from previously published work (Varshney et al., 2007) were screened for polymorphism between Falcon and Azhul using the ABI 3730XL genetic analyzer and previously described protocols for polymerase chain reaction and fragment discrimination (Chao et al., 2007). Alleles for each of the polymorphic markers were subsequently interrogated using the same protocols.

DArT genotyping was provided by Diversity Arrays Technology Pty Ltd (DArT P/L) (http://www.diversityarrays.com/index.html). DNA from each parental line and RIL was hybridized to the PstI(BstNI) v1.7 array which contains 2500 representations from a wide range of barley cultivars and accessions (Wenzl et al., 2006). Dominant genotypes were called using DArTsoft v.7 (Wenzl et al., 2006) and a binary data matrix was provided with various measures of quality and polymorphism information content for each marker.

SNP alleles were assayed via the Barley Oligo Pooled Assay 1 (BOPA1), which contains 1536 SNPs developed as part of the 
Barley Coordinated Agricultural Project (CAP) (http://barleycap.org). Details regarding SNP development and selection of high confidence SNPs from PilotOPAs (POPA) included in BOPA1 were described by Close et al. (2009). The prefix "MK." was added to the original SNP loci designation from BOPA1 for map visualization purposes. SNP genotyping was conducted at the USDA-ARS Small Grains Genotyping Center in Fargo, ND, using the GoldenGate assay and BeadArray platform developed by Illumina (Fan et al., 2003). Genotype calls were performed using Illumina's BeadStudio v3.1 software and calls were evaluated manually.

\subsection{Map construction}

MultiPoint (www.MultiQTL.com) was used to develop a map solution focused on marker stability. For the MultiPoint solution, analysis was performed as previously described (Mester et al., 2003a,b). First, maximum likelihood estimation was used to calculate pairwise recombination fractions $(r f)$ for all marker pairs, and preliminary clustering and linkage group assignment were determined at $r f=0.05$. To achieve correct resolution, closelylinked markers were grouped and represented by a delegate, or framework marker, with the highest information content. Iterative resampling was performed to simultaneously determine marker order and detect markers causing local map instability and expansion. Ambiguous markers were removed after each reordering sequence, and attached to an optimum interval on the completed framework. Stable linkage groups were merged endto-end by incrementally increasing $r f$, with a final $r f$ of 0.30 , and jackknife resampling was repeated to verify marker order and stability.

Framework markers and genotypes from the MultiPoint solution were used to test the new mapping features in JMP Genomics 5.1 (SAS Institute, Cary, NC), optimizing marker orders and
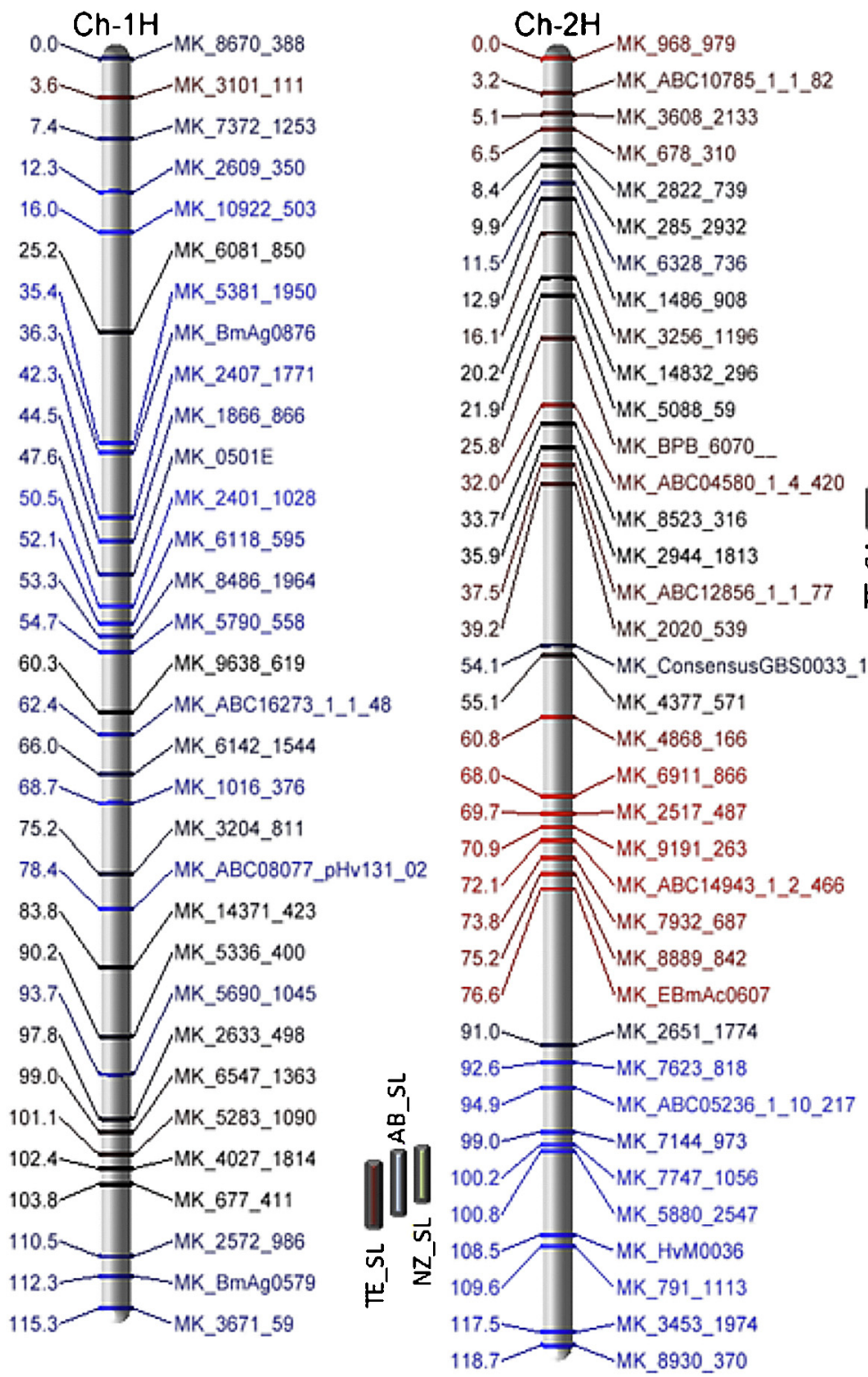

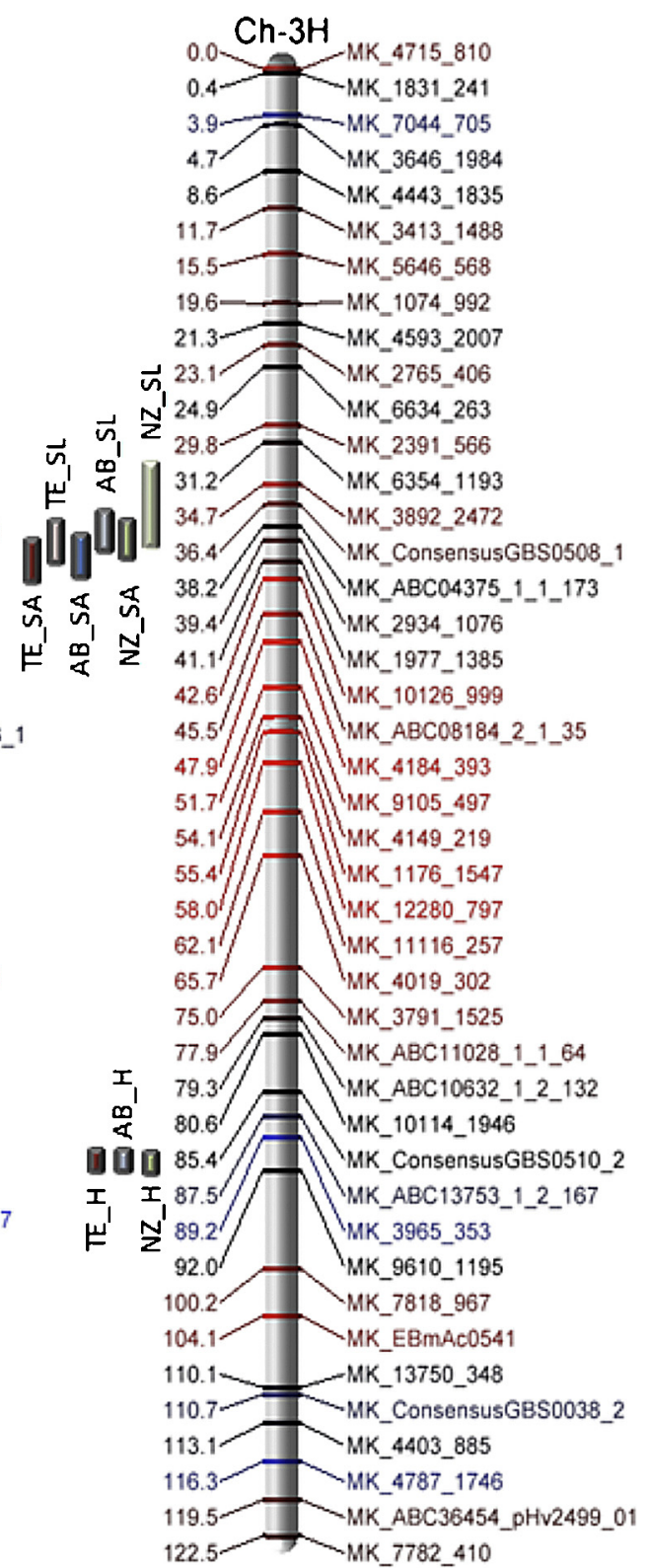

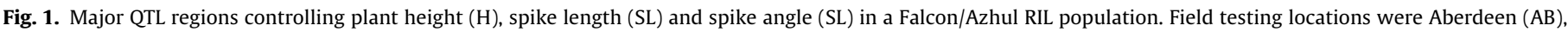

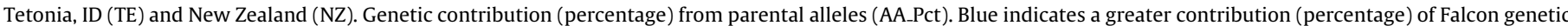

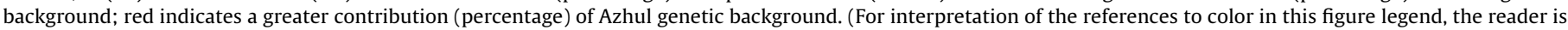
referred to the web version of the article.) 


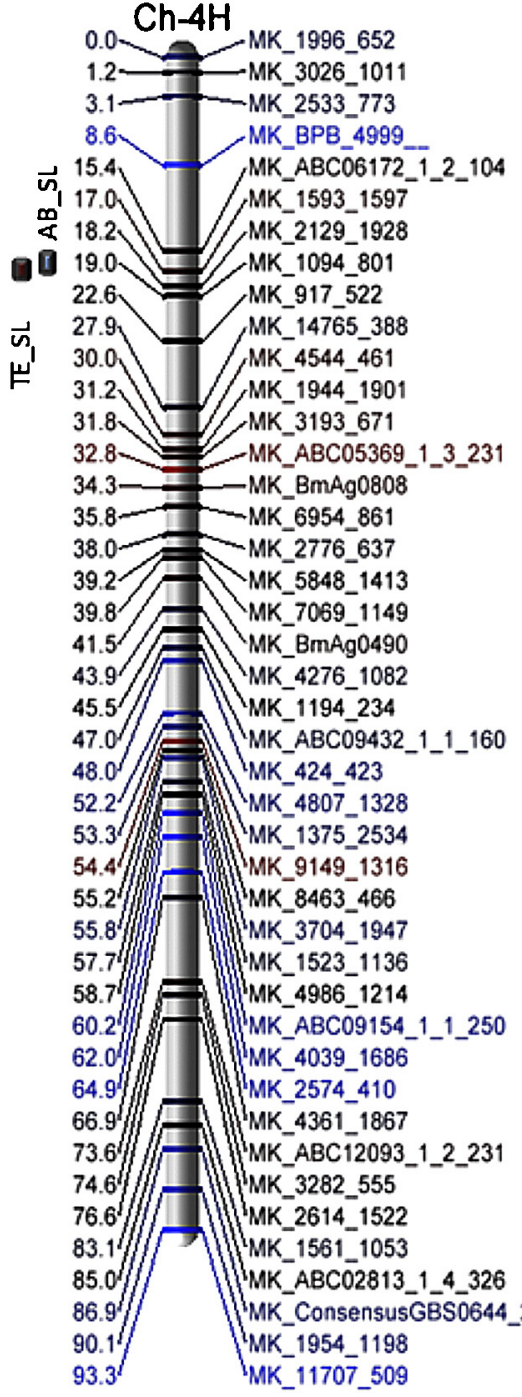

$\mathrm{Ch}-5 \mathrm{H}$

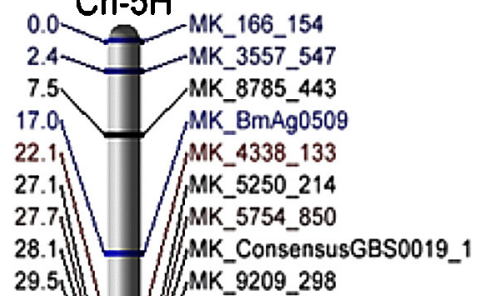

29.7 MK M 9209 _298

303

326.

34.1 $=$ MK_6035_654

35.6. MK 8320955

38.2. $=$ MK_1732_491

38.6 -11 MK $6820-586$

39.8 MK_2146_2256

40.4 1 MK_BmAg0477

40.9/ $=$ MK_1992_1714

41.7/ $/$ MK_2505_850

43.1/ Th_ABC09365_1_3_378

44.1/ I MK_1910_1343

45.7 $\Rightarrow$ MK_ABC11529_1_1_295

47.1 $\rightarrow$ MK_65_778

48.8

54.4// MK_6714_579

55.2

57.5 MK_3928_513

71.4 -MK_BmAg0584

$74.5-11$-MK_5004_375

76.8 1 -1LMK_4219_685

$79.3-11-M K K_{-} 10318$-572

80.5 - MK_3398_163

$82.6-12$ MK 6913 _ 1235

83.5 $\Rightarrow$ MK 6170304

85.4 $=1$ MK_4771_380

86.8 MK_ABC11221_1_3_410

88.0 MK_3478_1024

99.9 MK_ConsensusGBS0531_1

का 103.1 106.04 MK_211_259

106.6- - MK_5571_640

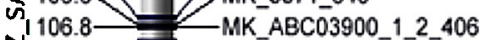

108.0 = MK 5156 -737

110.3 TMK 3412579

113.4-MK_1011_1338

117.5-_-MK_3477_1248

127.1 MK_3759_1385

128.1. MK_5893_1285

128.3. MK_2617_1234

128.9- $=$ MK_2290_796

131.6- IIICMK_4117_472

$132.8=-M K 6735754$

140.9 MK_15017_277

141.9. MK 5219.773

142.8. MK_2493_660

$143.0-$ MK_4658_1237 $_{127}$

$144.0 \rightarrow M K \_A B C 16075$ _2_2_232

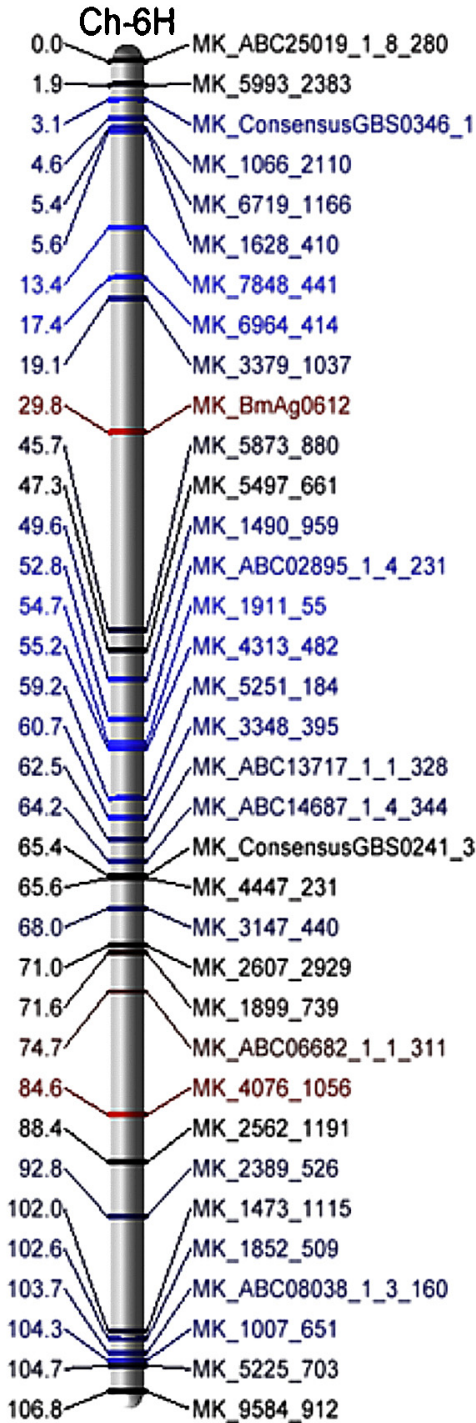

Fig. 1. (Continued)

distances. The final FA map was then visualized using the JMP Genomics high definition (HD) linkage map visualization tool with markers colored by segregation distortion.

\subsection{Marker/trait association}

Means, variances (genotype and location), correlations, and broad sense heritability estimates were calculated for plant height and spike length and angle for all locations using the JMP 9.0 statistical software (SAS Institute, Cary, NC). Broad sense heritability was calculated by dividing the genotypic variance by the total variance from a random effects model. The three phenotypes from each experiment were quantitatively mapped using WinQTL Cartographer (Wang et al., 2005). QTL analysis was done using the MultiPoint/JMP Genomics solution. Single marker analysis (SMA) and composite interval mapping (CIM) (Zeng, 1994) were performed for each measure. Stepwise regression with a threshold value of $P=0.05$ was used to choose co-factors for CIM. To identify significant QTL, experiment-wise significance levels were established by running 1000 permutations for all traits, $\alpha=0.05$ 


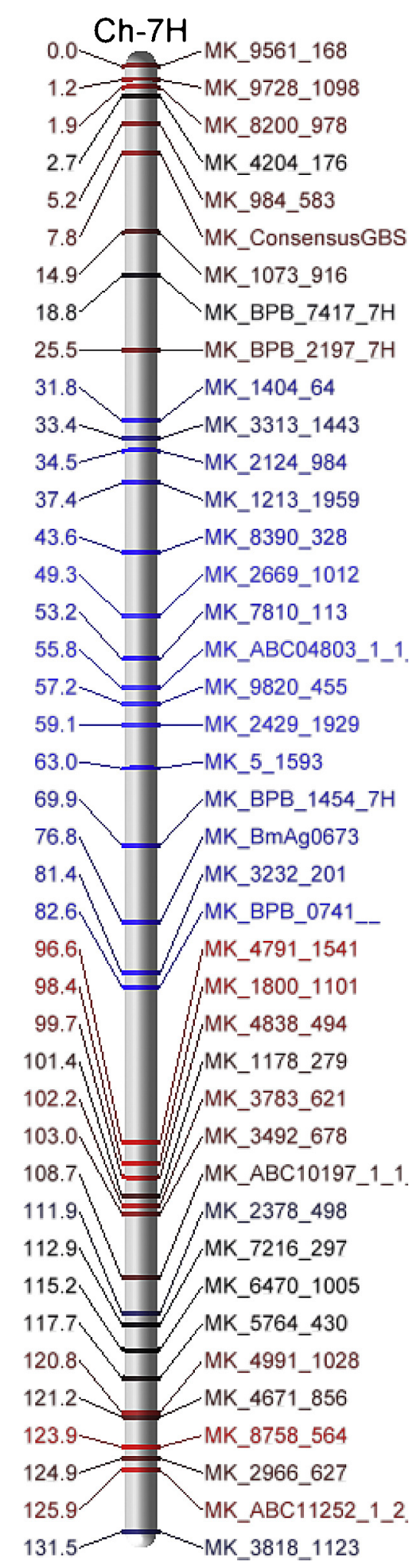

Fig. 1. (Continued)

(Churchill and Doerge, 1994). QTL intervals were assigned to the area within one LOD score of the QTL peak. In addition, QTL were considered major if they were identified in at least two environments tested in this study. Based on these results, major QTL alleles were inputted into multiple interval mapping (MIM) to estimate the total phenotypic variance accounted for by the QTL.

\section{Results}

\subsection{Phenotypic analysis}

Analysis of variance indicated that the effects of genotype and genotype*environment were significant for all three traits 
Table 1

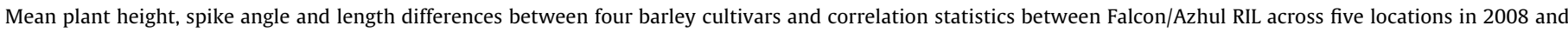
2009.

\begin{tabular}{|c|c|c|c|c|c|c|c|}
\hline \multirow[t]{2}{*}{ Location } & \multirow[t]{2}{*}{ Genotype } & \multirow[t]{2}{*}{ Height $^{A}(\mathrm{~cm})$} & \multicolumn{3}{|l|}{ Spike } & \multicolumn{2}{|c|}{ Correlation } \\
\hline & & & Angle $^{A}$ (degrees) & Length $^{A}(\mathrm{~cm})$ & $\mathrm{H}^{*} \mathrm{SA}$ & $\mathrm{H}^{*} \mathrm{SL}$ & $S A^{*} \mathrm{SL}$ \\
\hline \multirow{4}{*}{$\begin{array}{l}\text { Aberdeen, } \\
\text { ID }\end{array}$} & Falcon & $30.5 a$ & $94.2 \mathrm{a}$ & $8.9 b$ & & & \\
\hline & Azhul & $26.5 b$ & $26.7 c$ & $4.8 \mathrm{c}$ & & & \\
\hline & CDC Alamo & $32.5 a$ & $66.6 b$ & $12.3 a$ & & & \\
\hline & Baronesse & $33.0 \mathrm{a}$ & $94.2 \mathrm{a}$ & $7.9 \mathrm{~b}$ & & & \\
\hline \multirow[t]{2}{*}{ Mean } & & $30.6^{*}$ & $70.1^{*}$ & $8.5^{*}$ & $0.62^{* * *}$ & $0.76^{* * *}$ & $0.39^{* * *}$ \\
\hline & Falcon & $32.0 \mathrm{c}$ & $72.5 a$ & $7.9 b$ & & & \\
\hline \multirow{3}{*}{$\begin{array}{l}\text { Tetonia, } \\
\text { ID }\end{array}$} & Azhul & $26.0 \mathrm{~d}$ & $10.0 \mathrm{c}$ & $4.5 \mathrm{c}$ & & & \\
\hline & CDC Alamo & $36.0 \mathrm{a}$ & $42.2 \mathrm{~b}$ & $12.1 \mathrm{a}$ & & & \\
\hline & Baronesse & $34.0 \mathrm{~b}$ & 46.7a,b & 6.8a,b & & & \\
\hline Mean & & $32.0^{*}$ & $42.8^{* * * * *}$ & $7.8^{*}$ & $0.56^{* * *}$ & $0.90^{* * *}$ & $0.46^{* * *}$ \\
\hline \multirow{4}{*}{$\begin{array}{l}\text { Baton } \\
\text { Rouge, } \\
\text { LA }\end{array}$} & Falcon & $34.5 \mathrm{a}$ & $55.8 \mathrm{a}$ & $10.0 \mathrm{a}$ & & & \\
\hline & Azhul & $20.8 b$ & $23.3 b$ & $6.8 \mathrm{~b}$ & & & \\
\hline & CDC Alamo & $32.5 a$ & $44.5 b$ & $10.8 \mathrm{a}$ & & & \\
\hline & Baronesse & $34.0 \mathrm{a}$ & $48.3 a$ & 8.7a,b & & & \\
\hline Mean & & $30.4^{*}$ & $43.0^{* * * *}$ & $9.1^{*}$ & $0.34^{* * *}$ & $0.77^{* * *}$ & $0.35^{* * *}$ \\
\hline \multirow{4}{*}{$\begin{array}{l}\text { College } \\
\text { Station, } \\
\text { TX }\end{array}$} & Falcon & $25.5 a$ & $62.5 a$ & - & & & \\
\hline & Azhul & $26.9 a$ & $19.2 b$ & - & & & \\
\hline & CDC Alamo & $27.9 a$ & $58.9 a$ & - & & & \\
\hline & Baronesse & $31.0 \mathrm{a}$ & $55.0 \mathrm{a}$ & - & & & \\
\hline \multirow[t]{2}{*}{ Mean } & & $27.8^{*}$ & $48.9^{* * * *}$ & & $0.40^{* * *}$ & - & - \\
\hline & Falcon & $46.8 \mathrm{a}$ & $87.7 a$ & 9.9a & & & \\
\hline Leeston, & Azhul & $43.3 a$ & $15.8 \mathrm{~b}$ & $6.7 b$ & & & \\
\hline \multirow[t]{2}{*}{$\mathrm{NZ}$} & CDC Alamo & $35.0 \mathrm{~b}$ & $67.7 a$ & $10.9 a$ & & & \\
\hline & Baronesse & $36.0 \mathrm{~b}$ & $84.5 \mathrm{a}$ & $9.7 a$ & & & \\
\hline \multicolumn{2}{|l|}{ Mean } & $40.3^{*}$ & $63.4^{* *}$ & $9.3^{*}$ & 0.0 & $-0.26^{* * *}$ & $0.61^{* * *}$ \\
\hline \multicolumn{8}{|l|}{$\begin{array}{rl}{ }^{\mathrm{A}} & \text { Means follo } \\
{ }^{*} & p<0.05 . \\
& p<0.01 \\
& \\
{ }^{* * *} & <0.001 \\
& p<0.0001 .\end{array}$} \\
\hline
\end{tabular}

measured, while the location effect was only significant for spike angle $(\leq 0.001)$. This location effect was explained by the higher degree of mean spike angles $(P=0.05)$ in Aberdeen, ID and Leeston, NZ, compared to College Station, TX, Tetonia, ID, and Baton Rouge, LA (Table 1). Azhul had shortest stature, more acute spike angles, and shorter spikes $(P=0.05)$ across all locations, with the exception of College Station, TX and Leeston, NZ, where height differences between Azhul and at least one of the other lines did not differ (Table 1). In Aberdeen, CDC Alamo had more acute spike angles than all lines, while Falcon, Baronesse, and CDC Alamo did not differ for height or spike length. In Tetonia, CDC Alamo was significantly taller and had shorter spikes with acute angles. In Baton Rouge, LA, College Station, TX, and Leeston, NZ there were no differences in any of the three traits measured between Falcon, CDC Alamo, or Baronesse, with the exception of Falcon being significantly taller than CDC Alamo and Baronesse in New Zealand. All traits within a location were positively correlated $(P=0.0001)$, with the exception of height/spike angle and height/spike length in New Zealand, where height/spike angle was not significant and height/spike length was negatively correlated (Table 1).

Broad sense heritabilities were calculated for all three traits across the combined northern U.S. locations (Aberdeen and Tetonia, ID) and the two southern U.S. locations (Baton Rouge, LA and College Station, TX) since the locations represented spring and winter barley growing areas. The heritability of height $(83.7 \%)$ and spike angle (74.0\%) was higher for the combined northern locations than the combined southern locations (height $=15.0 \%$, spike angle $=35.0 \%$ ). Heritability of spike length was lower for the northern locations (54.4\%) versus the southern locations (76.0\%). Overall,
Table 2

Marker distribution on the recombination map for the Falcon/Azhul RIL population.

\begin{tabular}{lrrrc}
\hline Chromosome & Length & SNP & DArT & SSR \\
\hline $1 \mathrm{H}$ & 115.3 & 29 & 0 & 3 \\
$2 \mathrm{H}$ & 118.7 & 34 & 1 & 2 \\
$3 \mathrm{H}$ & 122.5 & 44 & 0 & 1 \\
$4 \mathrm{H}$ & 93.3 & 42 & 1 & 2 \\
$5 \mathrm{H}$ & 144.0 & 58 & 0 & 4 \\
$6 \mathrm{H}$ & 106.8 & 34 & 0 & 1 \\
$7 \mathrm{H}$ & 131.5 & 36 & 4 & 1 \\
Total & 832.1 & 277 & 6 & 14
\end{tabular}

the estimates show that all three traits were highly heritable across the spring locations, while only spike length was highly heritable in the winter.

\subsection{Map construction and comparison}

The Falcon/Azhul parental lines and RILs were genotyped with 1536 BOPA SNP markers, 2500 DArT markers and 100 microsatellites to provide data for high density mapping. Of these, 561 SNPs (36.5\%), 317 DArTs (12.7\%) and 39 microsatellites (39.0\%) were polymorphic, displayed minimal segregation distortion, and were scored on $\geq 0.90$ of the population. Of these 917 markers, 297 (32\%) were assembled into a stable order of seven linkage groups with a total map length of $832.1 \mathrm{cM}$ (Table 2). The framework markers consisted of 277 SNP (49.4\% of polymorphic SNP), 6 DArT (1.9\%) and 14 microsatellite (35.9\%). 


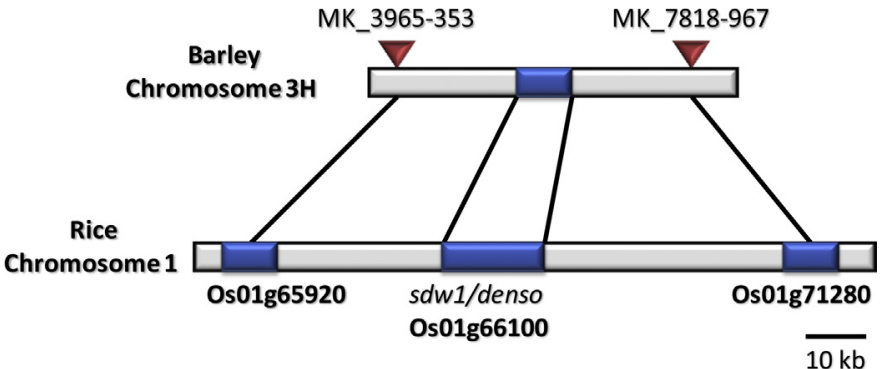

Fig. 2. Orthologous relationship between barley chromosome $3 \mathrm{H}$ and rice chromosome 1. Chromosome alignments were based on BOPA SNP sequences (MK). QTL alignment with the semidwarf gene ( $s d w 1$ ) was based on genetic distance (barley) to physical distance (rice).

Visualization tools in JMP Genomics 5.1 allow the coloring of markers along a linkage group by discrete or continuous indicators such as marker type and segregation distortion. In this study, we chose to color markers by segregation distortion to view the dominant allele, although markers with $\geq 0.375$ distortion were removed. Based on our analysis, markers along chromosome $1 \mathrm{H}$ were skewed toward the Falcon parental line, while markers along $3 \mathrm{H}$ were skewed toward the Azhul parental line. Markers along all other chromosomes showed mixed amounts of skewness within blocks toward both parental lines (Fig. 1).

\subsection{Marker/trait association}

Plant height $(\mathrm{H})$, spike length $(\mathrm{SL})$, and spike angle (SA) measurements from all five locations were combined with framework genotypes derived from the MultiPoint/JMP Genomics map. Based on QTL analysis of height $(\mathrm{H})$, a single region centered at $89.2 \mathrm{cM}$ on chromosome $3 \mathrm{H}$ was found that accounted for $31.0 \%$ of the height variation in Aberdeen (AB), 23.5\% in Tetonia (TE) and $40.0 \%$ in Leeston, New Zealand (NZ) (Table 3).

QTL analysis of spike length (SL) detected a single QTL on chromosomes $2 \mathrm{H}$ centered at $102.8 \mathrm{cM}, 3 \mathrm{H}$ centered at $38.2 \mathrm{cM}$, and $4 \mathrm{H}$ centered at $19.0 \mathrm{cM}$ in both Idaho locations and at the same location on $3 \mathrm{H}$ in New Zealand (Table 4). The QTL on $2 \mathrm{H}$ and $3 \mathrm{H}$ each accounted for approximately $20 \%$ of the phenotypic variation in both Idaho locations and $13.9 \%$ of the variation in New Zealand, while all three explained $43.4 \%$ and $38.9 \%$ of the phenotypic variation in Tetonia and Aberdeen, respectively (Table 4).

QTL analysis of spike angle (SA) detected single QTL on chromosome $3 \mathrm{H}$ centered at $38.2 \mathrm{cM}$ and on $5 \mathrm{H}$ centered at $106.7 \mathrm{cM}$ in both Idaho locations and New Zealand (Table 5 and Fig. 2). The QTL on $3 \mathrm{H}$ accounted for an average of $27.0 \%$ of the spike angle variation, while the QTL on $5 \mathrm{H}$ accounted for an average of $9.2 \%$ of the variation. Combined, the two QTL accounted for an average of $31.6 \%$ of the spike angle variation across the three environments.

\section{Discussion}

The goal of this study was to determine barley genetic regions associated with plant height and spike length and angle. The primary marker platforms chosen to derive genotypes for map construct were the BOPA Illumina SNP array developed by the Barley CAP and the DArT platform available commercially through Diversity Arrays Technology Pty Ltd (DArT P/L) (http://www.diversityarrays.com/index.html). In addition to these markers, we added microsatellite markers polymorphic between the parents of the population.

The mapping solution in this study produced a molecular linkage map spanning $832.1 \mathrm{cM}$, while the consensus map derived by Close et al. (2009) was $1099 \mathrm{cM}$ in total length. Comparison of the linkage map in this study to the barley consensus map (Close et al., 2009) revealed consistency in marker grouping and orders. Total map in this study contained 297 markers with an average marker density of $2.80 \mathrm{cM}$ per marker.

The HD map visualization of segregation ratios allowed simple characterization of marker distortion along the linkage map with regard to a specific parental line. Based on this, it was clear that marker blocks on chromosomes $1 \mathrm{H}, 4 \mathrm{H}$ and $6 \mathrm{H}$ were distorted toward the Falcon allele while marker blocks on chromosome $3 \mathrm{H}$ were distorted toward the Azhul allele. Marker blocks for each parental allele were observed on chromosomes $2 \mathrm{H}, 5 \mathrm{H}$ and $7 \mathrm{H}$. Overall, it appears that some unknown selection pressure influenced specific sections of each chromosome. This could be due, in part, to the intermating of siblings during population advancement.

Genetic intervals containing genes affecting plant height, spike length, and spike angle were discovered on four of seven chromosomes. Based on our results, a single QTL was detected on chromosome $3 \mathrm{H}(\sim 89.2 \mathrm{cM})$ affecting plant height. A previous study on barley plant height identified QTL on chromosome $1 \mathrm{H}$ at $131 \mathrm{cM}, 2 \mathrm{H}$ at $156 \mathrm{cM}, 3 \mathrm{H}$ at $51 \mathrm{cM}$ and $6 \mathrm{H}$ at $100 \mathrm{cM}$ (Chutimanitsakun et al., 2011). In Chutimanitsakun et al. study QTL on chromosome $3 \mathrm{H}$ was centered at $51 \mathrm{cM}$ and it had 2-LOD confidence interval between 43 and $60 \mathrm{cM}$. Our plant height QTL localized at $89.2 \mathrm{cM}$, which suggests that our QTL is a novel QTL. Furthermore, their plant height QTL is bordered by alm locus, which is placed in $3 \mathrm{H}-\mathrm{Bin} 3$ (next to btr1 locus) http://wheat.pw.usda.gov/ cgi-bin/graingenes/report.cgi? class=marker\&name=alm and by the marker FGX_OWB00380, which corresponds to marker 12_31017 located at $56.40 \mathrm{cM}$ on $3 \mathrm{H}$ (Close et al., 2009). Another study on barley plant height identified QTL on chromosome $3 \mathrm{H}$ at $67-78 \mathrm{cM}$ (Marquez-Cedillo et al., 2001). Comparison of QTL flanking markers, from Marquez-Cedillo et al. study and our study, in barley integrated genetic maps at the GrainGenes website (http://wheat.pw.usda.gov) suggested that our QTL was in a different genetic location than the QTL from Marquez-Cedillo et al. study. Localization of the QTL region in barley onto the rice annotated genome was enabled by flanking BOPA SNP sequences (Close et al., 2009) as described by Islamovic et al. (2013). The candidate $s d w 1 /$ denso gene (Jia et al., 2009) was identified (Fig. 2). Since Azhul was derived from a mutation population, a hypothesis is that a functional mutation occurred in the $s d w 1 /$ denso gene.

QTL on chromosomes $2 \mathrm{H}, 3 \mathrm{H}$, and $4 \mathrm{H}$ were detected for spike length, while QTL for spike angle were detected on chromosomes $3 \mathrm{H}$ and $5 \mathrm{H}$. Of these QTL, the strongest effect was observed impacting both traits in a novel location on chromosome $3 \mathrm{H}$ characterized by marker MK_ConsensusGBS0508-1 at $36.4 \mathrm{cM}$. MK_ConsensusGBS0508-1 is orthologous to rice Os01g12810. QTL for spike length on chromosome 3H was flanked by MK_ABC043751-1-173 marker at 38.2 cM which is orthologous to rice $0 s 01 \mathrm{~g} 40310$. This region contains a family of genes controlling plant elongation including an ethylene-response factor (Os01g13000). These genes are known to cause differential cell elongation resulting in apical hook bending (Li et al., 2004). Falcon spikes displayed arched or bent architecture compared to Azhul. Based on these observations, an attractive hypothesis would be that an allelic variant of an ethylene response factor in Falcon or Azhul is responsible for the arched phenotype reducing spike length and increasing spike angle as indicating by the additive effect in the QTL model.

The remaining QTL effecting spike length on chromosome $2 \mathrm{H}$ characterized by the SNP MK_7144-973 at $102.8 \mathrm{cM}$ and $4 \mathrm{H}$ characterized by the SNP MK_2129-1928 at $19.0 \mathrm{cM}$ were in regions previously identified (Xue et al., 2010). MK_7144973 is orthologous to rice 0 s04g43390, which is in a close proximity to rice auxin-responsive SAUR18 gene Os04g43740 implicated in plant growth. Auxin has significant effect on plant growth and development, specifically in vascular patterning and 
Table 3

QTL analysis summary for plant height $(\mathrm{cm})$ in the Falcon/Azhul $\mathrm{F}_{6: 8}$ RIL population grown across five locations in 2009.

\begin{tabular}{|c|c|c|c|c|c|}
\hline Location & $\mathrm{Ch}$ & QTL marker (peak position in $\mathrm{cM}$ ) & $\mathrm{LOD}^{\mathrm{b}}$ & $R^{2}(\%)^{\mathrm{c}}$ & Add. ${ }^{d}$ \\
\hline Tetonia, ID & $3 \mathrm{H}$ & MK_3965-353 (89.2) & 8.6 & 23.5 & 5.3 \\
\hline Aberdeen, ID & $3 \mathrm{H}$ & MK_3965-353 (89.2) & 12.4 & 31.0 & 6.1 \\
\hline Leeston, NZ & $3 \mathrm{H}$ & MK_3965-353 (90.2) & 20.5 & 40.0 & 2.0 \\
\hline
\end{tabular}

a Name of the flanking marker to the left of the QTL peak and interval (cM).

b QTL were detected using WinQTL Cartographer CIM and were based on a LOD threshold of 2.5 (1000 permutations and a type I error of 5\%).

c Percent of the phenotypic variation explained by the QTL.

d Total phenotypic variation explained by all QTL was calculated using WinQTL Cartographer MIM.

Table 4

QTL analysis summary for spike length $(\mathrm{cm})$ in the Falcon/Azhul $\mathrm{F}_{6: 8}$ RIL population grown across five locations in 2009.

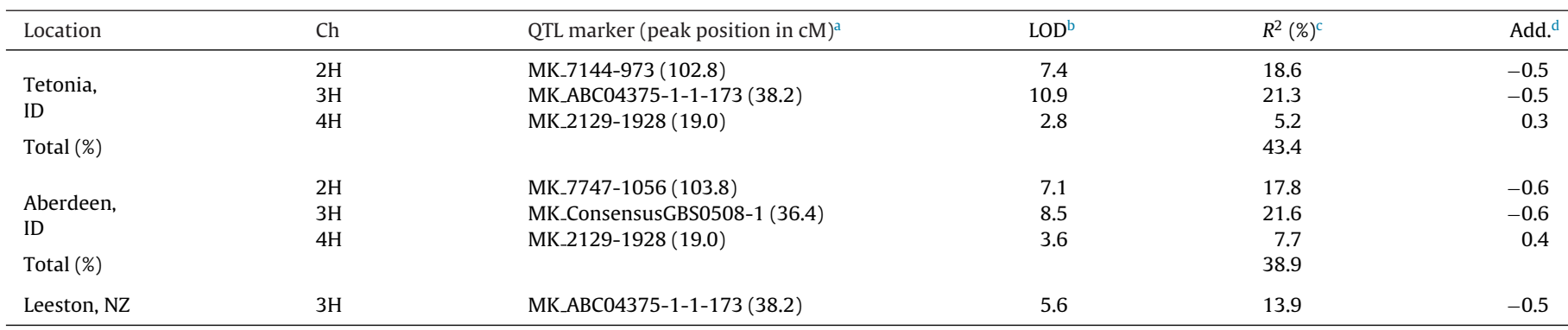

a Name of the flanking marker to the left of the QTL peak and interval (cM).

b QTL were detected using WinQTL Cartographer CIM and were based on a LOD threshold of 2.5 (1000 permutations and a type I error of 5\%).

c Percent of the phenotypic variation explained by the QTL.

d Total phenotypic variation explained by all QTL was calculated using WinQTL Cartographer MIM.

Table 5

QTL analysis summary for the degree of spike angle in the Falcon/Azhul $\mathrm{F}_{6: 8}$ RIL population grown across five locations in 2009

\begin{tabular}{|c|c|c|c|c|c|}
\hline Location & $\mathrm{CH}$ & QTL marker (peak position in $\mathrm{cM})^{\mathrm{a}}$ & $\mathrm{LOD}^{\mathrm{b}}$ & $R^{2}(\%)^{\mathrm{c}}$ & Add. $^{d}$ \\
\hline $\begin{array}{l}\text { Tetonia, } \\
\text { ID } \\
\text { Total (\%) }\end{array}$ & $\begin{array}{l}3 \mathrm{H} \\
5 \mathrm{H}\end{array}$ & $\begin{array}{l}\text { MK_ConsensusGBS0508-1 (36.4) } \\
\text { MK_5571-640 (106.7) }\end{array}$ & $\begin{array}{r}15.2 \\
3.9\end{array}$ & $\begin{array}{r}33.1 \\
7.2 \\
34.1\end{array}$ & $\begin{array}{r}-0.6 \\
0.3\end{array}$ \\
\hline $\begin{array}{l}\text { Aberdeen, } \\
\text { ID } \\
\text { Total (\%) }\end{array}$ & $\begin{array}{l}3 \mathrm{H} \\
5 \mathrm{H}\end{array}$ & $\begin{array}{l}\text { MK_ConsensusGBS0508-1 (36.4) } \\
\text { MK_ABC03900-1-2-406 (109.0) }\end{array}$ & $\begin{array}{l}8.6 \\
4.7\end{array}$ & $\begin{array}{l}23.1 \\
11.5 \\
30.9\end{array}$ & $\begin{array}{r}-1.0 \\
0.7\end{array}$ \\
\hline $\begin{array}{l}\text { Leeston, } \\
\text { NZ } \\
\text { Total (\%) }\end{array}$ & $\begin{array}{l}3 \mathrm{H} \\
5 \mathrm{H}\end{array}$ & $\begin{array}{l}\text { MK_3892-2472 (34.7) } \\
\text { MK_ConsensusGBS0531-1 (102.9) }\end{array}$ & $\begin{array}{r}10.9 \\
4.4\end{array}$ & $\begin{array}{r}24.7 \\
8.8 \\
29.7\end{array}$ & $\begin{array}{r}-1.0 \\
0.6\end{array}$ \\
\hline
\end{tabular}

a Name of the flanking marker to the left of the QTL peak and interval (cM).

b QTL were detected using WinQTL Cartographer CIM and were based on a LOD threshold of 2.5 (1000 permutations and a type I error of 5\%).

c Percent of the phenotypic variation explained by the QTL

d Total phenotypic variation explained by all QTL was calculated using WinQTL Cartographer MIM.

arrangement of phloem and xylem, which are essential elements of plants stem structure. In addition, this orthologous region also contains rice $0 s 07 g 49040$, which is upstream of pectinesterase gene (Os07g49100) showing involvement in plant stem growth. MK_2129-1928 is orthologous to two rice genes, Os03g49990 and Os11g31100. Os03g49990 gene encodes for a GRAS family transcription factor while 0 s11 331100 encodes for gibberellin-response modulator and both of those are involved in gibberellic acid signaling affecting plant growth. These results build strong evidence for the presence of genes controlling spike length in specific regions on chromosomes $2 \mathrm{H}$ and $4 \mathrm{H}$.

A novel QTL spanning 102.9-109 cM on chromosome $5 \mathrm{H}$ solely affecting spike angle was detected. This region was characterized by SNP markers MK_Consensus GBS0531-1, MK_5571-640 and MKABC03900-1-2-406. Based on orthologous relationships the region most likely contains clusters of auxin-responsive SAUR genes which are implicated in plant growth most notably causing bending, turning and directionalization of organs. A resulting hypothesis would suggest that an auxin-related allele from Falcon expressed in the peduncle causes a gravitrophic response resulting in greater spike angle as indicated by the additive effect.
Spike angle has been shown to reduce the severity of FHB based on the pleiotropic effect of less moisture in and around spikelets due to run off (Ma et al., 2000). In Ma et al., study, a barley variety "Chevron" showed resistance to the FHB and it had "nodding spike" or arched/obtuse spike angle (like Falcon), while barley variety Stander was susceptible to the FHB and it had "erect spike" or acute angle Our study provides SNP markers associated with the arched/obtuse spike angles in Falcon that were not observed in the Azhul parent or check varieties (Baroness and CDC Alamo). Currently, no information is available in regard to cv. Falcon, Azhul, Baroness and CDC Alamo resistance to the FHB to show correlation between spike angle and FHB resistance. However, if correlation exists, then these markers can be used to introgress this trait from Falcon to reduce FHB incidence while maintaining yields.

\section{Conclusions}

The BOPA1 that interrogates 1536 SNPs in tandem was a significant tool utilized in this study to generate an accurate map for barley, identify QTL controlling plant height and spike length and angle, identify candidate genes and a causal polymorphism 
through orthology with model species, and develop markers for introgression of key traits. This is the first report which combines barley consensus SNPs, DArTs and SSRs markers to determine QTL associated with barley height, spike length and angle. We report predictive assays for introgression of this trait for marker-assisted breeding. Two key hypotheses were developed in this study with regards to spike angle, an important trait for FHB tolerance. In addition, SNP markers linked to the key genetic region controlling spike angle were identified and are now available for use in breeding programs.

\section{Acknowledgements}

We thank and recognize the efforts of Irene Shackelford for development of the population and for her management of the Idaho field projects. In addition we thank Robert Campbell, Rebecca Caldera, Chris Evans, Kathy Satterfield and the staff of the University of Idaho Research and Extension Experiment Stations in Tetonia and Aberdeen, Idaho for field management. This work was funded by the USDA Barley for Rural Development Grant and the Idaho Barley Commission. The authors recognize and appreciate the support of Idaho barley growers and Ms. Kelly Olson.

\section{References}

Barua, U.M., Chalmers, K.J., Thomas, W.T.B., Hackett, C.A., Lea, V., Jack, P., Forester, B.P., Waugh, R., Powell, W., 1993. Molecular mapping of genes determining height, time to heading, and growth habit in barley (Hordeum vulgare). Genome $36,1080-1087$

Chao, S., Zhang, W., Dubcovsky, J., Sorrells, M., 2007. Evaluation of genetic diversity and genome-wide linkage disequilibrium among U.S. wheat (Triticum aestivum L.) germplasm representing different market classes. Crop Sci. 47, 1018-1030.

Churchill, G.A., Doerge, R.W., 1994. Empirical threshold values for quantitative trait mapping. Genetics 138, 963-971.

Chutimanitsakun, Y., Nipper, R.W., Cuesta-Marcos, A., Cistué, L., Corey, A., Filichkina, T., Johnson, E.A., Hayes, P.M., 2011. Construction and application for QTL analysis of a Restriction Site Associated DNA (RAD) linkage map in barley. BMC Genomics 12,4

Close, T.J., Bhat, P.R., Lonardi, S., Wu, Y., Rostoks, N., Ramsay, L., Druka, A., Stein, N., Svensson, J.T., Wanamaker, S., Bozdag, S., Roose, M.L., Moscou, M.J., Chao, S., Varshney, R.K., Szucs, P., Sato, K., Hayes, P.M., Matthews, D.E., Kleinhofs, A., Muehlbauer, G.J., DeYoung, J., Marshall, D.F., Madishetty, K., Fenton, R.D., Condamine, P., Graner, A., Waugh, R., 2009. Development and implementation of high-throughput SNP genotyping in barley. BMC Genomics 10, 582.

Dahleen, L.S., Morgan, W., Mittal, S., Bregitzer, P., Brown, R.H., Hill, N.S., 2012. Quantitative trait loci (QTL) for Fusarium ELISA compared to QTL for fusarium head blight resistance and deoxynivalenol content in barley. Plant Breed. 131, 237-243.

Fan, J.B., Oliphant, A., Shen, R., Kermani, B.G., Garcia, F., Gunderson, K.L., Hansen, M. Steemers, F., Butler, S.L., Deloukas, P., Galver, L., Hunt, S., McBride, C., Bibikova, M., Rubano, T., Chen, J., Wickham, E., Doucet, D., Chang, W., Campbell, D., Zhang, B., Kruglyak, S., Bentley, D., Haas, J., Rigault, P., Zhou, L., Stuelpnagel, J., Chee, M.S., 2003. Highly parallel SNP genotyping. Cold Spring Harb. Symp. Quant. Biol. $68,69-78$

Franckowiak, J.D., Pecio, A., 1992. Coordinator's report: a listing of genetic stocks. Barley Genet. Newsl. 21, 116-126.

Gottwald, S., Stein, N., Borner, A., Sasaki, T., Graner, A., 2004. The gibberellic-acid insensitive dwarfing gene sdw3 of barley is located on chromosome $2 \mathrm{HS}$ in a region that shows high colinearity with rice chromosome 7L. Mol. Gen. Genet. 271, 426-436.

Hearnden, P.R., Eckermann, P.J., McMichael, G.L., Hayden, M.J., Eglinton, J.K., Chalmers, K.J., 2007. A genetic map of 1000 SSR and DArT markers in a wide barley cross. Theor. Appl. Genet. 115, 383-391.

Helliwell, C.A., Chandler, P.M., Poole, A., Dennis, E.S., Peacock, W.J., 2001. The CYP88A cytochrome P450 ent-kaurenoic acid oxidase, catalyzes three steps of the gibberellin biosynthesis pathway. PNAS 98, 2065-2070.

Helm, J.H., Cortez, M.J., Salmon, D.F., Jedel, P.E., Stewart, W.M., 1996. Registration of 'Falcon' barley. Crop Sci. 36, 807.

Islamovic, E., Obert, D.E., Oliver, R.E., Harrison, S.A., Ibrahim, A., Marshall, J.M., Miclaus, K.J., Hu, G., Jackson, E.W., 2013. Genetic dissection of grain betaglucan and amylose content in barley (Hordeum vulgare L.). Mol. Bread. 31, $15-25$.

Jia, Q., Zhang, J., Westcott, S., Zhang, X.Q., Bellgard, M., Lance, R., Li, C., 2009. GA20 oxidase as a candidate for the semidwarf gene sdw1/denso in barley. Funct. Integr. Genomics 9, 255-262.
Kleinhofs, A., Kilian, A., Saghai-Maroof, M.A.,Biyashev, R.M.,Hayes, P., Chen, F. Q., Lapitan, N., Fenwick, A., Blake, T.K., Kanazin, V., Ananiev, E., Dahleen, L., Kudrna, D. Bollinger, J., Knapp, S.J., Liu, B., Sorrells, M., Heun, M., Franckowiak, J.D., Hoffman, D., Skadsen, R., Steffenson, B.J., 1993. A molecular isozyme and morphological map of the barley (Hordeum vulgare) genome. Theor. Appl. Genet. 86, 705-712.

Laurie, D.A., Pratchett, N., Romero, C., Simpson, E., Snape, J.W., 1993. Assignment of the denso dwarfing gene to the long arm of chromosome $3(3 \mathrm{H})$ of barley by use of RFLP markers. Plant Breed. 111, 198-203.

Li, H., Johnson, P., Stepanova, A., Alonso, J.M., Ecker, J.R., 2004. Convergence of signaling pathways in the control of differential cell growth in Arabidopsis. Dev. Cell 7, 193-204

Ma, Z., Steffenson, B.J., Prom, L.K., Lapitan, N.L., 2000. Mapping of quantitative trait loci for fusarium head blight resistance in barley. Phytopathology 90, 1079-1088

Marcel, T.C., Varshney, R.K., Barbieri, M., Jafary, H., de Kock, M.J.D., Graner, A., Niks, R.E., 2007. High-density consensus map of barley to compare the distribution of QTLs for partial resistance of Puccinia hordei A and of defense gene homologues. Theor. Appl. Genet. 114, 487-500.

Marquez-Cedillo, L.A., Hayes, P.M., Kleinhofs, A., Legge, W.G., Rossnagel, B.G., Sato K., Ullrich, S.E., Wesenberg, D.M., 2001. QTL analysis of agronomic traits in barley based on the double haploid progeny of two elite North American varieties representing different germplasm groups. Theor. Appl. Genet. 103, 625-637.

McMullen, M., Jones, R., Gallenberg, D., 1997. Scab of wheat and barley: a reemerging disease of devastating impact. Plant Disease 81, 1340-1348.

Mester, D., Ronin, Y., Minkov, D., Nevo, E., Korol, A.B., 2003a. Constructing largescale genetic maps using an evolutionary strategy algorithm. Genetics 165 , 2269-2282.

Mester, D.I., Ronin, Y.I., Hu, Y., Peng, J., Nevo, E., Korol, A.B., 2003b. Efficient multipoint mapping: making use of dominant repulsion-phase markers. Theor. Appl. Genet. $107,1002-1112$

Peng, J., Richards, D.E., Hartley, N.M., Murphy, G.P., Devos, K.M., Flintham, J.E., Beales, J., Fish, L.J., Worland, A.J., Pelica, F., Sudhakar, D., Christou, P., Snape, J.W., Gale, M.D., Harberd, N.P., 1999. Green revolution genes encode mutant gibberellins response modulators. Nature 400, 256-261.

Potokina, E., Druka, A., Luo, Z., Wise, R., Waugh, R., Kearsey, M., 2008. Gene expression quantitative trait locus analysis of 16,000 barley genes reveals a complex pattern of genome-wide transcriptional regulation. Plant J. 53, 90-101.

Rostoks, N., Mudie, S., Cardle, L., Russell, J., Ramsay, L., Booth, A., Svensson, J.T., Wanamaker, S.I., Walia, H., Rodriguez, E.M., Hedley, P.E., Liu, H., Morris, J., Close, T.J., Marshall, D.F., Waugh, R., 2005. Genome-wide SNP discovery and linkage analysis in barley based on genes responsive to abiotic stress. Mol. Genet. Genomics $274,515-527$

Sakamoto, T., Miura, K., Itoh, H., Tatsumi, T., Ueguchi-Tanaka, M., Ishiyama, K., Kobayashi, M., Agrawal, G.K., Takeda, S., Abe, K., Miyao, A., Hirochika, H., Kitano H., Ashikari, M., Matsuoka, M., 2004. An overview of gibberellin metabolism enzyme genes and their related mutants in rice. Plant Physiol. 134, 1-12.

Sasaki, A., Ashikari, M., Ueguchi-Tanaka, M., Itoh, H., Nishimura, A., Swapan, D. Ishiyama, K., Saito, T., Kobayashi, M., Khush, G.S., Kitano, H., Matsuoka, M., 2002. A mutant gibberellin-synthesis gene in rice. Nature 416, 701-702.

Sato, K., Nankaku, N., Takeda, K., 2009. A high density transcript linkage map of barley derived from a single population. Heredity 103, 110-117.

Spielmeyer, W., Ellis, M.H., Chandler, P.M., 2002. Semidwarf (sd-1), green revolution rice, contains a defective gibberellin 20-oxidase gene. PNAS 99, 9043-9048

Spielmeyer, W., Ellis, M., Robertson, M., Ali, S., Lenton, J.R., Chandler, P.M., 2004 Isolation of gibberellin metabolic pathway genes from barley and comparative mapping in barley, wheat and rice. Theor. Appl. Genet. 109, 847-855.

Stein, N., Prasad, M., Scholz, U., Thiel, T., Zhang, H., Wolf, M., Kota, R., Varshney, R.K., Perovic, D., Grosse, I., Graner, A., 2007. A 1,000-loci transcript map of the barley genome: new anchoring points for integrative grass genomics. Theor Appl. Genet. 114, 823-839.

Szűcs, P., Blake, V.C., Bhat, P.R., Close, T.J., Cuesta-Marcos, A., Muehlbauer, G.J., Ramsay, L.V., Waugh, R., Hayes, P.M., 2009. An integrated resource for barley linkage map and malting quality OTL alignment. Plant Genome 2, 134-140.

Varshney, R.K., Marcel, T.C., Ramsay, L., Russell, J., Roder, M.S., Stein, N., Waugh, R. Langridge, P., Niks, R.E., Graner, A., 2007. A high density barley microsatellite consensus map with 775 SSR loci. Theor. Appl. Genet. 114, 1091-1103.

Wang, S., Basten, C.J., Zeng, Z.B., 2005. Windows QTL Cartographer 2. 5. Dept. Statistics, North Carolina State University, Raleigh, Available at statgen.ncsu.edu/qtlcart/WQTL-Cart.htm

Wenzl, P., Li, H., Carling, J., Zhou, M., Raman, H., Paul, E., Hearnden, P., Maier, C., Xia, L., Caig, V., Ovesná, J., Cakir, M., Poulsen, D., Wang, J., Raman, R., Smith, K.P. Muehlbauer, G.J., Chalmers, K.J., Kleinhofs, A., Huttner, E., Kilian, A., 2006. A highdensity consensus map of barley linking DArT markers to SSR, RFLP and STS loci and agricultural traits. BMC Genomics 7, 206.

Xue, D., Zhou, M., Zhang, X., Chen, S., Wei, K., Zeng, F., Mao, Y., Wu, F., Zhang, G., 2010. Identification of OTLs for yield and yield components of barley under different growth conditions. J. Zhejiang Univ. Sci. B. 11, 169-176.

Yoshida, M., Kawada, N., Tohnooka, T., 2005. Effect of row type, flowering type and several other spike characters on resistance to fusarium head blight in barley. Euphytica 141, 217-227.

Zeng, Z., 1994. Precision mapping of quantitative trait loci. Genetics 136, 1457-1468. 